ISSN = 1980-993X-doi:10.4136/1980-993X
www.agro.unitau.br/ambi-agua
E-mail: ambi-agua@agro.unitau.br
Tel.: (12) 3625-4116

\title{
Disposição no solo de efluentes de esgoto tratado visando à redução de coliformes termotolerantes \\ (doi:10.4136/ambi-agua.63)
}

\author{
Teresa Blandina Castro Ribas ${ }^{1}$; Paulo Fortes Neto ${ }^{2}$ \\ ${ }^{1}$ Bióloga, M. Sc. em Ciências Ambientais da Universidade de Taubaté, SP \\ E-mail: teresaribas.castro@gmail.com \\ ${ }^{2}$ Eng. Agrônomo, Dr. Professor do Curso de Pós-Graduação em Ciências Ambientais da Universidade de \\ Taubaté, SP \\ E-mail: paulofortes.neto@gmail.com
}

\section{RESUMO}

O lançamento indiscriminado nos corpos d’água de esgotos domésticos sem tratamento, ou mesmo tratados, mas sem desinfecção apropriada, contribui com quantidade significativa de organismos do chamado "grupo coliforme", entre os quais agentes específicos de doenças de veiculação hídrica podem estar presentes. A aplicação no solo de efluentes de esgotos domésticos devidamente tratados, em vez de sua disposição direta em cursos d'água, além de ser uma maneira alternativa para disposição de resíduos e controle biológico de poluentes, constitui um modo adequado de fornecimento de nutrientes ao solo e às plantas. Este trabalho teve como objetivo avaliar a redução de coliformes termotolerantes após aplicações no solo de efluente de esgoto doméstico tratado por um período de 60 dias, associando os valores obtidos ao adensamento de rizobactérias Pseudomonas fluorescens e Bacillus spp. presentes nas rizosferas de diferentes culturas. O experimento foi desenvolvido em área da Fazenda Piloto do Departamento de Ciências Agrárias da Universidade de Taubaté e o Delineamento Experimental constou de blocos casualizados com cinco tratamentos envolvendo o cultivo de aveia, cevada, triticale, feijão preto e solo sem cultivo (Testemunha), totalizando 20 parcelas de solo classificado como Latossolo Vermelho Amarelo Distrófico. Os resultados obtidos por meio de análises microbiológicas de amostras de solo rizosférico e não rizosférico apresentaram um maior adensamento de rizobactérias na rizosfera da aveia. Entretanto, a maior eficiência obtida na redução de coliformes termotolerantes foi alcançada nos tratamentos envolvendo feijão preto e solo sem cultivo.

Palavras-chave: disposição no solo; fitorremediação; esgoto; coliformes; Pseudomonas; Bacillus.

\section{Controlled disposal of domestic effluent sewage in the ground to reduce fecal coliforms}

\begin{abstract}
The indiscriminate launching in water bodies of domestic sewage without treatment, or even treated, but without appropriate disinfection, contributes with significant amount of organisms of the called "coliform group" that can carry specific illnesses agents propagated through the water. The application of effluent in the ground, instead of direct disposal in water courses, in addition to being an alternative way for the disposal of residues and biological control of pollutants, constitutes an adequate way of nutrients supply to the soil and
\end{abstract}


plants. So, this work had as objective the evaluation of the reduction of fecal coliforms, after controlled applications of 60 days treated effluent in cultivated soil, by analyzing the increase of fluorescent rhizobacterias Pseudomonas fluorescens and Bacillus spp. present in the rhizospheres of different crops. The experiment was developed in field conditions in the Experimental Farm of Department of Agrarian Sciences of the University of Taubaté, municipality of Taubaté, SP. The Experimental design consisted of random blocks, with five treatments including annual crops (Oats, Barley, Triticale - a cross between wheat and rye, Black Beans and non-cultivated soil as witness - blank reference) and four repetitions, totalizing 20 ground plots with area of $2 \mathrm{~m} \mathrm{x} 1 \mathrm{~m}$ with $50 \mathrm{~cm}$ space among plots on a Dystrophic Red-Yellow Latossol. Results from the microbial analyses of rhizosphere and non-rhizosphere soil indicated that the rhizosphere of oats had denser rhizobacterias than the other crops. However, the greatest efficiency was found in the reduction of thermo-tolerant coliforms for both black beans and non-cultivated soil.

Keywords: application in the ground; sewage; wastewater; coliforms; rhizobacterias.

\section{INTRODUÇÃO}

O efluente doméstico, por ser um resíduo altamente poluidor, tem nos últimos anos demandado pesquisas com ênfase no desenvolvimento de tecnologias adequadas e de baixo custo para o tratamento e disposição de águas residuárias.

O lançamento indiscriminado nos corpos d'água de esgotos domésticos sem tratamento, ou mesmo tratados, mas sem desinfecção apropriada, contribui com quantidade significativa de organismos do chamado "grupo coliforme", entre os quais agentes específicos de doenças de veiculação hídrica podem estar presentes.

A aplicação do efluente no solo, em vez de sua disposição direta em cursos d'água, além de ser uma maneira alternativa para disposição de resíduos e controle biológico de poluentes, constitui um modo adequado de fornecimento de nutrientes ao solo (Fonseca, 2000).

Ao entender o solo como um elemento depurador e o sistema solo-planta como um reator renovável, reator este regido pelas leis da natureza, pode-se entender também, nesse contexto, os esgotos como fonte de energia, e não como um grande problema ambiental.

O solo é o habitat natural para uma grande variedade de organismos, tanto microrganismos, quanto animais invertebrados. Esse conjunto que vive e é responsável por inúmeras funções do solo é chamado de microbiota do solo e apresenta uma grande variedade de tamanhos e metabolismos.

Os microrganismos são extremamente diversos com várias centenas de espécies de fungos e uma grande diversidade de tipos de bactérias com populações que variam de $10^{6}$ a $10^{9}$ células por centímetro cúbico (Swift et al., 1979).

Uma das tecnologias para tratamento de efluentes sanitários empregada, embora não seja nova, mas que tomou impulso nos últimos dez anos, é a Fitorremediação, uma vez que a zona radicular das plantas, chamada de rizosfera, apresenta uma capacidade de transformar moléculas orgânicas exógenas em fontes de nutrientes para os diversos microrganismos que habitam nessa região (Dinardi et al., 2007). Trata-se de uma estratégia in situ que envolve o emprego de espécies vegetais adequadas e microrganismos a elas associados com o fim de degradar, reter e remover poluentes orgânicos e inorgânicos do solo e água.

A colonização da rizosfera - área ao redor das raízes - deve-se a uma maior disponibilidade de nutrientes em relação ao solo não-rizosférico.

Bactérias do grupo fluorescente do gênero Pseudomonas e gênero Bacillus spp. caracterizam-se por serem os dois mais abundantes gêneros de microrganismos presentes nos 
solos, sendo considerados importantes agentes de controle biológico, pois podem suprimir patógenos da rizosfera, por meio de mecanismos de inibição que incluem predação, competição por espaço e nutrientes, produção de antibióticos, ácido cianídrico e sideróforos, que são compostos de baixo peso molecular, quelantes de ferro, produzidos pela maioria das bactérias sob condições limitantes desse elemento. Podem ainda atuar como biorremediadores de áreas contaminadas, por degradarem substâncias xenobióticas.

$\mathrm{Na}$ variedade de microrganismos conhecidos que sintetizam sideróforos além das bactérias já mencionadas do gênero Pseudomonas e Bascillus spp., estão incluídas, também, várias bactérias entéricas; bactérias patogênicas de humanos do sub-grupo coliformes termotolerantes, dentre elas Escherichia coli, Salmonella typhimurim e Aerobacter aerogenes (Benite e Machado, 2002).

Sendo assim, dada a relevância e atualidade da problemática da contaminação dos recursos naturais pela prática de descarte de efluentes domésticos no solo, o objetivo deste trabalho foi verificar se a disposição no solo de efluentes de esgoto doméstico tratado favorece o adensamento de rizobactérias do gênero Pseudomonas do grupo fluorescente e do gênero Bacillus spp., associando os valores obtidos com a redução de coliformes termotolerantes presentes no efluente tratado.

\section{MATERIAL E MÉTODOS}

\subsection{Localização e instalação do experimento}

O experimento foi conduzido em condições de campo na Fazenda-Piloto do Departamento de Ciências Agrárias da Universidade de Taubaté, Município de Taubaté, Estado de São Paulo. Localizado nas Coordenadas Geográficas 2302'34”S e 45³1'02”W, com altitude média de 577 m e distante 140 km da cidade de São Paulo.

O clima local de acordo com a Classificação de Köpen (1948) é do tipo Cwa (Subtropical), com chuvas de verão e com uma precipitação média anual de $1300 \mathrm{~mm}$.

O solo da área experimental é classificado como Latossolo Vermelho-Amarelo distrófico, de textura argilo-arenosa, constituído por perfil não hidromórfico, profundo, de fertilidade natural baixa, cuja característica química determinada na camada de 0-20 cm de profundidade está apresentada na Tabela 1:

Tabela 1. Característica Química Natural do solo da área experimental.

\begin{tabular}{|c|c|c|c|c|c|c|c|c|c|c|c|c|c|}
\hline $\mathrm{pH}$ & $\begin{array}{l}\text { MO } \\
\text { (a) } \\
\mathrm{g} / \mathrm{dm}^{3}\end{array}$ & $\begin{array}{c}\mathrm{P} \\
\mathrm{mg} / \mathrm{dm}^{3}\end{array}$ & K & Ca & $\mathrm{Mg}$ & $\mathrm{H}+\mathrm{Al}$ & $\begin{array}{l}\text { SB } \\
\text { (D) }\end{array}$ & $\begin{array}{l}\text { CTC } \\
\text { (c) }\end{array}$ & B & $\mathrm{Cu}$ & $\mathrm{Fe}$ & $\mathrm{Mn}$ & $\mathrm{Zn}$ \\
\hline 7,1 & 15 & 8 & 1,4 & 95 & 12 & 11 & 108,4 & 119,4 & 0,13 & 0,8 & 25 & 6,0 & 1,4 \\
\hline
\end{tabular}

Fonte: Laboratório de Análises de Solos e Plantas - Depto. de Ciências Agrárias da UNITAU.

(a) MO = Matéria Orgânica; (b) SB = Soma de bases; (c) CTC = Capacidade de troca catiônica.

O delineamento experimental foi composto por blocos casualizados, com cinco tratamentos e quatro repetições (Figura 1), perfazendo assim um total de 20 parcelas. As parcelas de 2 x $1 \mathrm{~m}$ foram construídas com $50 \mathrm{~cm}$ de distância entre si e os blocos separados com distância de $1 \mathrm{~m}$.

Os estudos foram iniciados em maio de 2007, com a demarcação das 20 parcelas e coletas de amostras de solo na camada de $0-20 \mathrm{~cm}$ em todas as parcelas para realização de análise de propriedades químicas antes da aplicação do efluente. A semeadura foi realizada em junho com o cultivo de quatro culturas. 
Das quatro culturas utilizadas no experimento, três espécies foram da família das Gramíneas, a aveia (Avena fafua) - Tratamento 1; a cevada (Hordum vulgar) - Tratamento 2 e o triticale (Triticosecale Wittmack) - Tratamento 4. A quarta espécie utilizada foi da família das Leguminosas, o feijão preto (Phaseolus vulgaris L.), Tratamento 3. Como Testemunha foi utilizado solo sem cultivo - Tratamento 5.

O espaçamento utilizado para cultivo das gramíneas dentro de cada parcela foi de $20 \mathrm{~cm}$ e para a leguminosa o espaçamento foi de $40 \mathrm{~cm}$. A irrigação das culturas com água encanada foi realizada duas vezes por semana, teve como objetivo favorecer a germinação das sementes e, posteriormente, manutenção das plantas. A aplicação do efluente de esgoto tratado, seguindo a técnica de irrigação superficial, foi realizada com periodicidade de 60 dias e com intervalos de vinte dias entre cada aplicação, totalizando três aplicações. A primeira aplicação ocorreu 30 dias após a semeadura.

O efluente de esgoto utilizado no experimento foi proveniente do sistema de tratamento por leito cultivado implantado no Departamento de Ciências Agrárias - UNITAU, o qual trata o esgoto dos sanitários, laboratórios e cozinha existentes no prédio central do Departamento. A composição do efluente é basicamente advinda da higiene humana, tendo pouca contribuição de produtos químicos das atividades laboratoriais. Apresentou $\mathrm{pH}$ de 7,2 e Demanda Química de Oxigênio (DQO) de 324 mg.L ${ }^{-1}$.

O Sistema de tratamento de esgoto por leito cultivado estruturalmente é composto por um tanque séptico (Tratamento primário), construído em concreto armado e com $30 \mathrm{~m}^{3}$ de capacidade, dois filtros anaeróbios compartimentados, instalados em duas caixas d'água de cimento amianto de $1 \mathrm{~m}^{3}$ cada e preenchidos com brita $\mathrm{n}^{\circ} 2$. Sendo o primeiro filtro de fluxo descendente seguido do segundo por fluxo ascendente (Tratamento secundário) e o leito cultivado (Tratamento secundário), construído em concreto armado, preenchido com brita $\mathrm{n}^{\circ}$ 2 e capacidade de $15 \mathrm{~m}^{3}$.

A espécie vegetal utilizada para compor o leito e cultivada diretamente sobre a brita foi a Zantedeschia aethiopica, conhecida popularmente como Copo-de-leite.

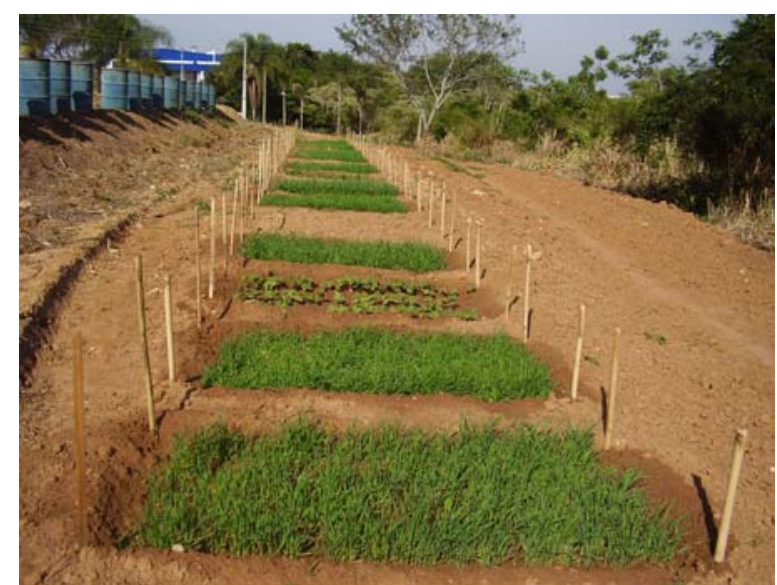

Figura 1. Vista do experimento, composto por cinco tratamentos com quatro repetições. Sendo quatro tratamentos com solo cultivado (aveia, cevada, triticale e feijão preto) e um tratamento sem cultivo (Testemunha).

O volume de efluente de esgoto tratado aplicado em cada tratamento foi de 170 litros por parcela de solo. Utilizou-se uma mangueira de $3 / 4$ " conectada a saída do leito cultivado para o enchimento de 20 tambores de 200 litros, posicionados a frente de cada uma das parcelas, dos tambores o efluente foi distribuído superficialmente por meio de mangueiras de $1 / 2$ ”. 


\subsection{Monitoramento/ Procedimentos para amostragens e Análises microbiológicas}

\subsubsection{Solo}

Para coletas de amostras de solos rizosféricos, foram retiradas de cada parcela cultivada 6 plantas com torrão de solo aderido às raízes, acondicionadas em sacos plásticos identificados e levadas ao Laboratório de Microbiologia Agrícola e Fitopatologia do Depto. de Ciências Agrárias da UNITAU.

As raízes de cada uma das 6 amostras por parcela foram agitadas vigorosamente para desprender o solo que estava aderido e homogeneizadas, formando uma amostra composta por parcela. Das parcelas não cultivadas, foram retiradas amostras de solo na camada de 0-20 $\mathrm{cm}$ e realizados os mesmos procedimentos descritos acima.

Foram pesadas $10 \mathrm{~g}$ de cada amostra composta e colocadas em frascos com capacidade de $90 \pm 2 \mathrm{~mL}$ com tampa de rosca, contendo solução salina esterilizada (solução tampão de Fosfato Monopotássico e Cloreto de Magnésio). A partir daí prepararam-se diluições em série de fator 10 da suspensão de solo obtida para análises de bactérias dos gêneros Pseudomonas spp., Bacillus spp. e Coliformes termotolerantes (Escherichia coli).

Para análise química do solo, foram pesadas novamente $10 \mathrm{~g}$ de cada amostra de solo, acondicionadas em sacos plásticos identificados e levadas ao Laboratório de Análises de Solo e Plantas do Depto de Ciências Agrárias da UNITAU para realização da avaliação das características químicas do solo após aplicação do efluente.

\subsubsection{Contagem de bactérias do grupo fluorescente do gênero Pseudomonas}

Alíquotas de $0,1 \mathrm{~mL}$ de cada diluição $10^{-2}, 10^{-3}$ e $10^{-4}$, foram transferidas para as placas de Petri contendo meio de cultura B de King (King et al., 1954) e espalhadas com alça de Drigalski em triplicata. As placas foram mantidas a $28^{\circ} \mathrm{C} \pm 2^{\circ} \mathrm{C}$ por 72 horas. Após o período de incubação as colônias foram observadas sob incidência de luz ultravioleta no interior da câmera negra, para avaliação da presença ou não de um halo esverdeado fluorescente, característico das Pseudomonas fluorescens. Na Figura 2, é mostrada uma placa de Petri contendo três colônias de bactérias do grupo fluorescente do gênero Pseudomonas com halos esverdeados fluorescentes.

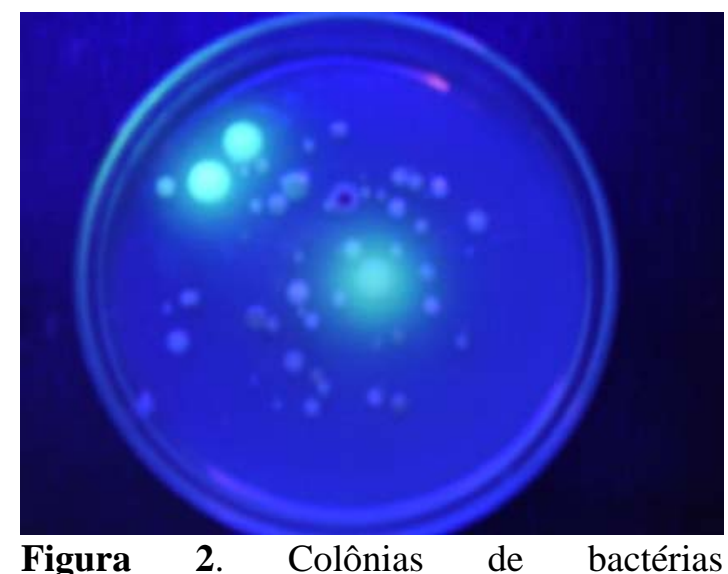

Figura 2. Colônias de bactérias Pseudomonas fluorescens observadas sob incidência de luz ultravioleta - Laboratório de Microbiologia Agrícola e Fitopatologia UNITAU. 


\subsubsection{Contagem de bactérias do gênero Bacillus}

O procedimento utilizado para contagem de Bacillus spp. foi semelhante ao descrito no item 2.2.1.1 para contagem de Pseudomonas, só que as diluições em série foram colocadas em banho maria a $\pm 80^{\circ} \mathrm{C}$ por 20 minutos e resfriadas a temperatura ambiente antes de serem transferidas para as placas de Petri.

Alíquotas de $0,1 \mathrm{~mL}$ das diluições $10^{-3}, 10^{-4}$ e $10^{-5}$, com três repetições, foram transferidas para placas de Petri contendo meio de cultura BDA (Batata Dextrose Agar). A contagem de colônias que cresceram em meio de cultura BDA foi feita após incubação a $\pm 28^{\circ} \mathrm{C}$ por 72 horas. Os resultados estão expressos em unidades formadoras de colônias por grama de solo seco (UFC/g solo seco).

\subsubsection{Contagem de Coliformes termotolerantes}

A metodologia empregada para a contagem do número mais provável (NMP) de Coliformes termotolerantes seguiu o preconizado no Standard Methods for the Examination of Water and Wastwater. (APHA, 2000), utilizando-se a Técnica de Tubos Múltiplos (TTM).

Para o Teste Presuntivo para contagem de bactérias do grupo coliformes, utilizou-se meio de cultura Caldo Lactosado e para o Teste Confirmativo para Coliformes termotolerantes, especificamente para Escherichia coli, o meio E.C..

Alíquotas de $1 \mathrm{~mL}$ dos frascos contendo amostras de solo dos 20 tratamentos diluídas em solução salina nas séries $10^{-1}, 10^{-2}, 10^{-3}, 10^{-4}, 10^{-5}$ e $10^{-6}$, foram inoculadas na série de 5 tubos para cada diluição contendo meio caldo lactosado. Foi efetuada a incubação à $35^{\circ} \mathrm{C} \pm 0,5^{\circ} \mathrm{C}$ durante 24/48 horas e ao final feita a $1^{\text {a }}$ leitura ainda do ensaio presuntivo.

Considera-se o resultado positivo à fermentação do meio evidenciada pela produção do gás. Com o uso de alça de platina, fez-se a inoculação do material dos tubos positivos para cada tubo correspondente do meio E.C. Após a transferência, os tubos contendo amostras positivas em meio E.C. foram transferidos para incubadora a $44,5^{\circ} \mathrm{C} \pm 0,5$ por um período adicional de $24 \pm 2$ horas.

A densidade de coliformes foi expressa em N.M.P. de coliformes termotolerantes por 100 mL de água, o qual é obtido por meio de tabela no Standard Methods (APHA, 2000).

\subsubsection{Efluente de esgoto tratado}

Para amostragem de efluente proveniente da ETE por leito cultivado, procedeu-se à coleta de $100 \mathrm{~mL}$ de água residuária em frasco com tampa esterilizado na saída do sistema. A amostra foi levada ao Laboratório de Microbiologia Agrícola e Fitopatologia para realização dos procedimentos para as análises microbiológicas para contagem de unidades formadoras de colônias de rizobactérias Pseudomonas fluorescens, Bacillus spp. e o número mais provável de coliformes termotolerantes.

A realização das análises microbiológicas do efluente de esgoto tratado seguiram os mesmos procedimentos e técnicas descritos nos itens acima para análises microbiológicas de solo.

\section{RESULTADOS E DISCUSSÃO}

A temperatura média e umidade relativa do ar registradas durante o período de desenvolvimento do experimento foram de $32^{\circ} \mathrm{C}$ e $28 \%$, respectivamente. Esses valores indicam a predominância de dias quentes e baixa umidade do ar durante o desenvolvimento do projeto. Não houve ocorrência de chuvas na época de coletas de amostras de solo para análises microbiológicas do solo nos 20 e 40 dias após o início das aplicações de efluente. 
Entretanto, na época de realização da coleta de amostras de solo, 60 dias após a primeira irrigação foram registradas chuvas de baixa intensidade.

Esses fatores físicos, como elevada temperatura ambiente, baixa umidade do ar e baixa precipitação pluviométrica podem ter interferido significativamente na sobrevivência de coliformes termotolerantes no solo, inviabilizando condições favoráveis ao seu crescimento. Já a ocorrência de chuvas aumentando a umidade do solo associada à matéria orgânica proveniente do efluente pode ter criado condições favoráveis à sobrevivência de coliformes termotolerantes, inclusive, possibilitando o aumento de sua concentração.

Os resultados da densidade de colônias de Pseudomonas fluorescens e Bacillus spp. em unidades formadoras de colônias por grama de solo seco (UFC.g ${ }^{-1}$ ) e do número mais provável de coliformes termotolerantes por grama de solo seco (NMP.g ${ }^{-1}$ ), obtidos em cada tratamento foram submetidos ao Teste de Duncan a 5\% de probabilidade e são apresentados a seguir nas Figuras 3, 4, 5, 6 e 7, e discutidos ao longo deste capítulo.

As análises microbiológicas do efluente de esgoto tratado realizadas antecedendo as amostragens de solo, respectivamente aos 20, 40 e 60 dias apresentaram valor médio de concentração de coliformes termotolerantes de 1 x $10^{6} \mathrm{NMP} / 100 \mathrm{~mL}$ de efluente.

A Figura 3 apresenta a concentração de coliformes termotolerantes verificada em cada um dos tratamentos, após a terceira aplicação de efluente, o que corresponde a 60 dias após a primeira aplicação e período de 120 dias do ciclo vegetativo das culturas.

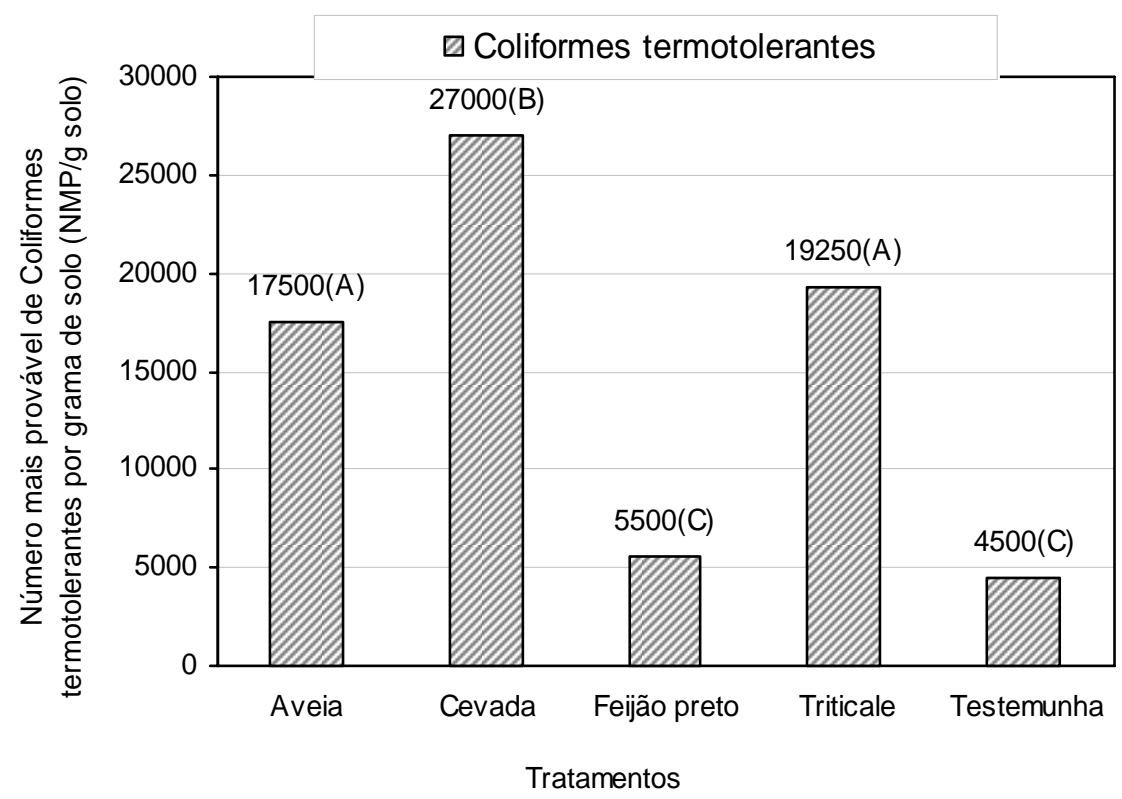

Figura 3. Valores Médios do Número Mais Provável de coliformes termotolerantes na camada de $0-20 \mathrm{~cm}$ de profundidade de solo cultivado com diferentes culturas e testemunha, tratado com aplicações de efluente de esgoto doméstico, 60 dias após a primeira aplicação. Médias seguidas de letras maiúsculas iguais, não diferem significativamente entre si pelo teste de Duncan a $5 \%$ de probabilidade.

Nas análises microbiológicas de amostras de solo realizadas 20 e 40 dias após a primeira aplicação de efluente não foi constatada a existência de coliformes termotolerantes no solo em todos os tratamentos, o que pode ser entendido como resultado da atuação das rizobactérias Pseudomonas fluorescens e Bacillus spp., entre outros microrganismos presentes não avaliados neste trabalho, por meio de mecanismos antagonistas, predação, competição, 
antibiose e produção de sideróforos, visto o teor de ferro presente no solo no local do experimento ser de $25 \mathrm{mg} / \mathrm{dm}^{3}$, considerado pelo Sistema IAC como baixo teor.

A reduzida concentração de matéria orgânica no solo variando de 15 a $19 \mathrm{mg} / \mathrm{dm}^{3}$, pode ser considerada como fator de competição por nutrientes entre a população de rizobactérias e coliformes. Assim, como investigado por Butler et al. (1954) ao aplicarem esgoto sanitário tratado na superfície de um solo argilo-arenoso e verificaram que, a partir de $3 \mathrm{~m}$ no perfil do solo, os coliformes fecais não conseguem sobreviver, provavelmente em razão da ausência do material orgânico, fundamental para a sua sobrevivência.

Entretanto, nas análises microbiológicas 60 dias após as três aplicações verificou-se que os tratamentos envolvendo a aveia e o triticale apresentaram valores de coliformes termotolerantes entre $17,5 \times 10^{3}$ e 19,0 x10³ NMP/100 ml de água residuária, o que resultou numa eficiência de $98,0 \%$ na redução de coliformes termotolerantes; a cevada apresentou valor de 27 x10 $\mathrm{NMP} / 100 \mathrm{~mL}$ de água, o que corresponde a uma eficiência na redução de coliformes termotolerantes de $97,0 \%$; e o feijão preto e testemunha apresentaram valores entre $6,0 \times 10^{3}$ e 9,0 x10 $\mathrm{NMP} / 100 \mathrm{~mL}$ registrando uma eficiência de 99,4\% na redução de coliformes termotolerantes. As diferenças de valores obtidos nos tratamentos aveia e triticale não foram significativos, já a cevada mostrou a menor eficiência e os melhores resultados na redução de coliformes termotolerantes foram obtidos nos tratamentos com feijão preto e solo sem cultivo.

Observa-se que os melhores resultados na redução de coliformes termotolerantes foram obtidos até 40 dias após as aplicações de efluente, coincidindo com o pleno desenvolvimento vegetativo das culturas utilizadas, ou seja, 90 dias, em que há a maior produção de exsudados pelas raízes das plantas e, conseqüentemente, maior adensamento de microrganismos nas rizosferas e no solo.

Esses resultados estão de acordo com estudos de Zavaleta-Mejia e Van Gundy (1982); Becker et al. (1988), os quais mostram que as bactérias são os organismos mais abundantes na rizosfera das plantas e podem apresentar efeito antagônico a vários patógenos.

Resultados similares foram obtidos por McGauher e Krone (1967) ao estudarem a remoção de coliformes fecais durante a percolação de água residuária por meio do perfil do solo, identificando confinamento das bactérias na camada de 0,0 a 0,9 m e a redução de $64 \%$ no nível populacional, após 12 dias.

Já a constatação de coliformes após 60 dias coincide com o término do ciclo, no qual o número de colônias de bactérias nas rizosferas se encontrava muito reduzido. Nesse período a maior eficiência na redução de coliformes foi alcançada nos tratamentos envolvendo feijão preto, o qual apresenta ciclo vegetativo de 90 dias em relação à aveia, à cevada e ao triticale que é de 120 dias e testemunha.

Em concordância com Chernicharo (1997), o qual menciona sobre a atuação de fatores físicos, tais como: umidade, $\mathrm{pH}$, radiação solar, temperatura e concentração de matéria orgânica influenciando no tempo de sobrevivência dos coliformes no ambiente, acredita-se que os resultados obtidos neste experimento estejam também relacionados a fatores físicos, como temperatura e umidade. Já que a arquitetura da planta do feijão confere menor sombreamento, assim como, o solo sem cobertura vegetal (testemunha) propiciam maior exposição solar, elevando a temperatura e reduzindo a umidade no solo, resultando em condições desfavoráveis à sobrevivência e ao desenvolvimento de coliformes termotolerantes.

O controle biológico de nematóides não é restrito apenas às interações entre esses fitopatógenos e seus antagonistas, mas ambos são influenciados pela planta, pelo ambiente físico e pelas microflora e microfauna do solo (Stirling, 1991).

Uma rizobactéria do grupo das fluorescentes, três Pseudomonas não fluorescentes e uma Bacillus spp. reduziram em até 53\% o número de galhas de $M$. incógnita em tomateiros, sendo as mais eficientes entre as 156 testadas por Habte e Byappanahalliu (1994). 
Rizobactérias do gênero Bacillus também estão freqüentemente associadas ao controle de nematóides, mas outros gêneros também se mostram promissores (Sikora, 1992).

A Figura 4 apresenta os valores médios obtidos em quatro repetições dos cinco tratamentos da quantidade de colônias de Pseudomonas fluorescens e Bacillus spp. presentes nas rizosferas das culturas e testemunha, antes da primeira irrigação.

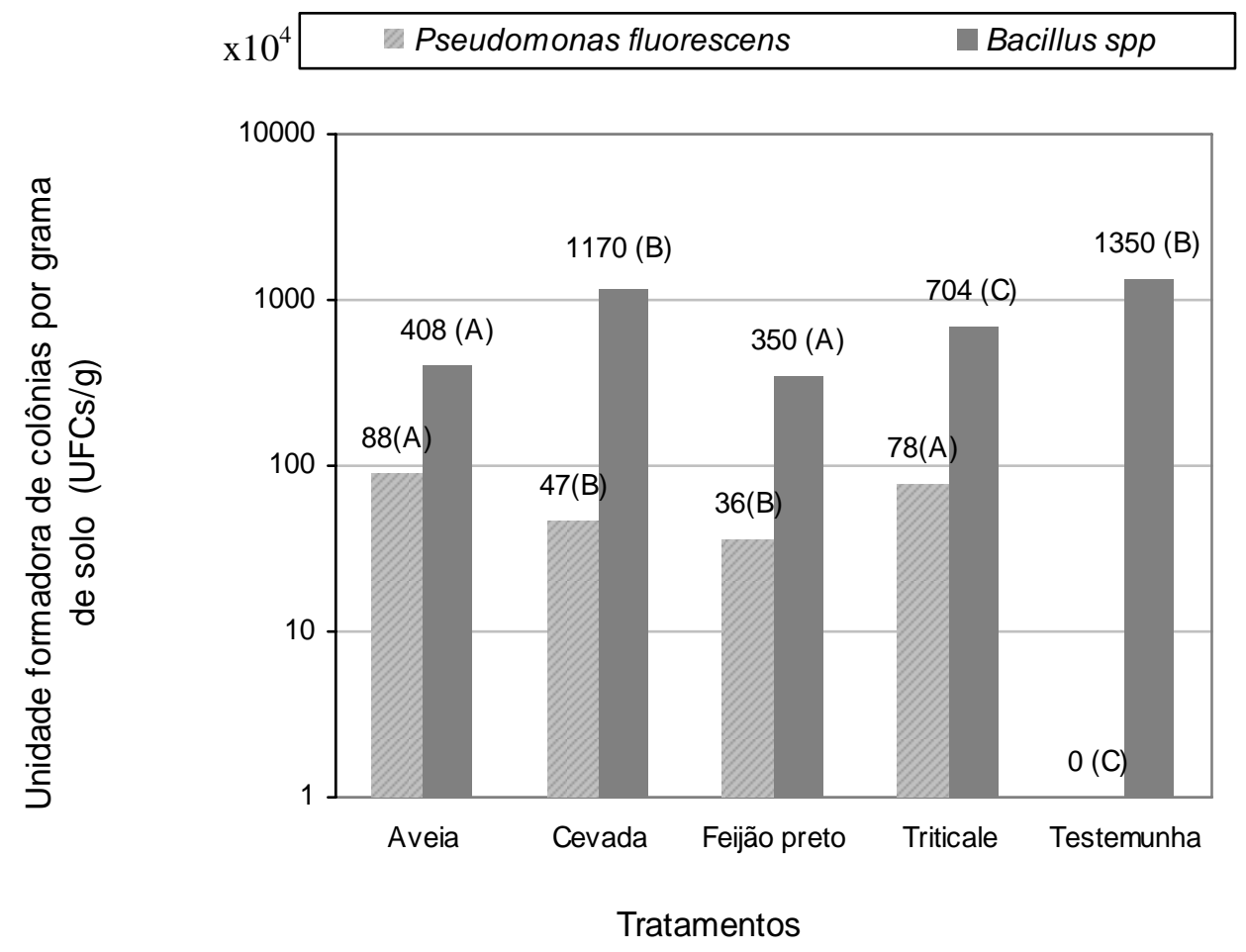

Figura 4. Valores médios de Unidades formadoras de colônias de Pseudomonas fluorescens e Bacillus spp. na camada de 0-20 cm de profundidade de solo cultivado com diferentes culturas e testemunha, antes da aplicação de efluente doméstico tratado. Médias seguidas de letras maiúsculas iguais não diferem significativamente entre si pelo teste de Duncan a 5\% de probabilidade.

Antecedendo a aplicação de efluente tratado no solo, verificou-se a inexistência de colônias de Pseudomonas fluorescens no tratamento testemunha. Contrariamente, a quantidade de Bacillus spp. presente foi a maior em relação aos demais tratamentos envolvendo solos cultivado.

Nos tratamentos com aveia e triticale, registraram-se os maiores valores entre $78 \times 10^{4} \mathrm{e}$ $88 \times 10^{4}$ unidades formadoras de colônias por grama de solo seco (UFCs. ${ }^{-1}$ ) de Pseudomonas fluorescens; nos tratamentos com cevada e feijão preto registraram-se quantidades menores entre $36 \times 10^{4}$ e $47 \times 10^{4}$ UFCs.g $^{-1}$. Esses resultados indicam que as rizosferas da aveia e triticale possibilitam uma maior colonização de rizobactérias Pseudomonas fluorescens, o que possivelmente esteja relacionado às substâncias exsudadas por suas raízes.

Em relação à quantidade de Bacillus spp., observou-se uma maior quantidade populacional na rizosfera da Cevada com valores médios próximos dos valores médios da testemunha. Os demais tratamentos apresentaram valores médios aproximados.

De qualquer forma, em todos os tratamentos, verificou-se que a quantidade de colônias de Bacillus spp. antes mesmo da aplicação de efluente já era superior ao número de colônias de Pseudomonas. Esses dados estão de acordo com Stainer et al. (1966), de que os Bacillus spp. são resistentes ao calor e a outros agentes destrutivos devido a sua característica de 
formar endósporos. A maioria deles tem exigências nutricionais simples, requerendo no máximo alguns aminoácidos ou vitaminas B como fatores de crescimento.

$\mathrm{Na}$ Figura 5, verificam-se os valores médios do adensamento de colônias de Pseudomonas fluorescens e Bacillus spp. por tratamento, 20 dias após a primeira irrigação com o efluente e com 80 dias de ciclo vegetativo das culturas.

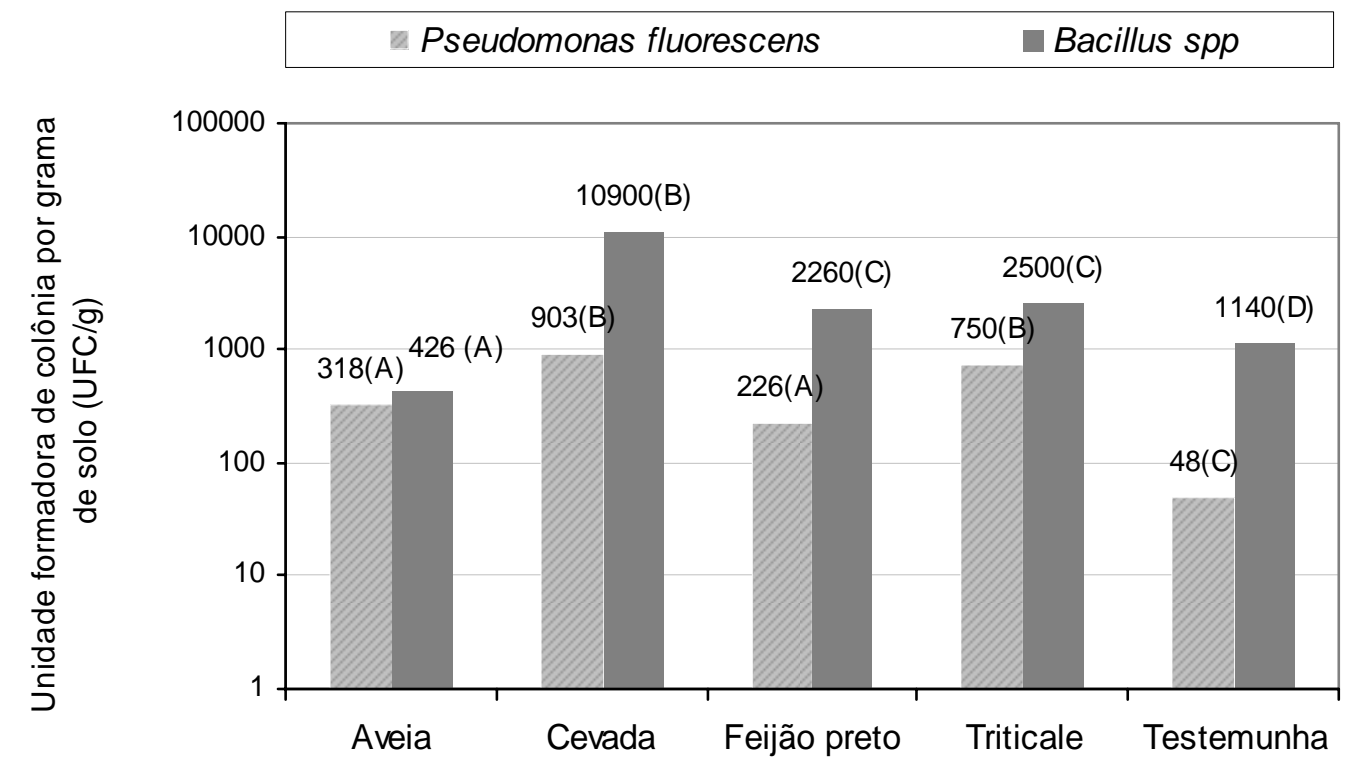

Tratamentos

Figura 5. Valores médios de Unidades formadoras de colônias de Pseudomonas fluorescens e Bacillus spp. na camada de $0-20 \mathrm{~cm}$ de profundidade de solo cultivado com diferentes culturas e testemunha, 20 dias após a primeira aplicação de efluente de esgoto doméstico tratado. Médias seguidas de letras maiúsculas iguais não diferem significativamente entre si pelo teste de Duncan a 5\% de probabilidade.

Os resultados obtidos mostraram um adensamento significativo de $P$. fluorescens em todos os tratamentos, inclusive o surgimento de colônias na testemunha de $48 \times 10^{4}$ unidades formadoras de colônias por grama de solo (UFCs.g ${ }^{-1}$ ). A cevada apresentou uma quantidade de $903 \times 10^{4}\left(\mathrm{UFC}^{-1}\right)^{-}$e o triticale de $750 \times 10^{4} \mathrm{UFC}^{-1}$; a aveia e o feijão preto apresentaram valores médios aproximados de 318 x10 ${ }^{4}$ UFC. g ${ }^{-1}$ e 226 x10 ${ }^{4}$ UFC.g $^{-1}$, respectivamente. Acredita-se que os adensamentos verificados em todos os tratamentos estejam relacionados ao aporte de matéria orgânica ao solo após a irrigação com o efluente de esgoto, além da liberação de grande quantidade de exsudados pelas rizosferas das plantas durante o desenvolvimento de seus ciclos vegetativos.

Esses resultados confirmam a afirmação de Stirling (1991), de que dentre as rizobactérias, o grupo das Pseudomonas fluorescentes é o mais consistentemente isolado, principalmente durante os períodos de grande produção de exsudados radiculares.

Em relação ao adensamento de Bacillus spp., verificou-se um notável crescimento do número de colônias nos tratamentos envolvendo solos cultivados, o que não ocorreu na testemunha. Uma possível hipótese para entendimento desse resultado é a de que o surgimento de colônias e $P$. fluorescens no solo sem cultivo tenha promovido uma competição, já anteriormente descrita, não somente entre P.fluorescens e Bacillus spp. e coliformes termotolerantes, como também, entre os dois gêneros de rizobactérias.

A Figura 6 mostra os valores médios de unidades formadoras de colônias de Pseudomonas fluorescens e Bacillus spp., obtidos 40 dias após a primeira irrigação com o 
efluente de esgoto tratado e com desenvolvimento de 100 dias de ciclo vegetativo das culturas.

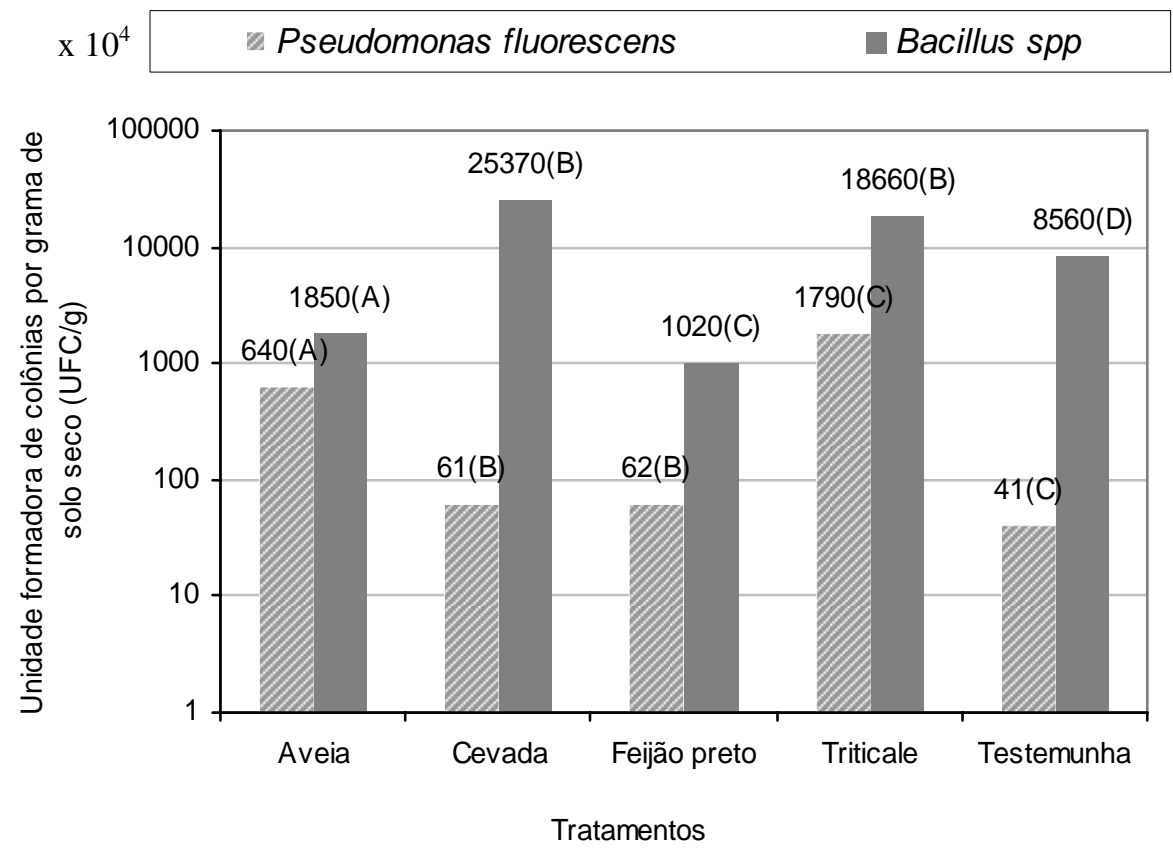

Figura 6. Valores médios de Unidades formadoras de colônias de Pseudomonas fluorescens e Bacillus spp. na camada de $0-20 \mathrm{~cm}$ de profundidade de solo cultivado com diferentes culturas e testemunha, 40 dias após a primeira aplicação de efluente de esgoto doméstico tratado. Médias seguidas de letras maiúsculas iguais não diferem significativamente entre si pelo teste de Duncan a 5\% de probabilidade.

Os resultados obtidos 40 dias após a primeira irrigação, equivalente a vinte dias após a segunda aplicação de efluente, mostraram que os tratamentos envolvendo a aveia e o triticale continuaram apresentando um aumento no adensamento de colônias de $P$. fluorescens, enquanto as rizosferas da aveia e feijão preto tiveram seu número de colônias significativamente reduzido, sendo de $903 \times 10^{4}$ para $61 \times 10^{4} \mathrm{UFc}^{-1}{ }^{-1}$ solo para a aveia e de $226 \times 10^{4}$ para $62 \times 10^{4}$ UFC.g ${ }^{-1}$ solo para o feijão preto. Na testemunha não ocorreu alteração significativa de valores médios.

Uma das hipóteses para a interpretação desses resultados seja a de que as análises realizadas 40 dias após a primeira aplicação coincidiram com 100 dias do ciclo vegetativo das culturas empregadas no experimento, visto que a família das gramíneas possui um ciclo de 120 dias e as leguminosas de 90 dias. Sendo assim, o feijão preto já se encontrava-se com seu ciclo vegetativo encerrado, enquanto a aveia, a cevada e o triticale ainda se encontravam na fase de amadurecimento. Entretanto, os resultados obtidos com a cevada, apesar de espécie vegetal da família das gramíneas, deve ter relação com uma redução acentuada e antecipada na produção de exsudados em relação à aveia e ao triticale.

Estes resultados atendem ao descrito por Clays-Josserand et al. (1995) de que o favorecimento de uma determinada espécie fluorescente de Pseudomonas spp. depende das características do solo e da espécie da planta e que seu desenvolvimento é maior na região das rizosferas do que em solos sem cultivo.

Coelho. (2006) detectaram que a rizosfera da alface favoreceu o crescimento de bactérias fluorescentes do gênero Pseudomonas, em comparação com o crescimento de Bacillus spp., que não foi beneficiado. Esse favorecimento foi detectado por comparação da rizosfera da alface com a da chicória (Cicorium endiva), rúcula (Eruca sativa), salsa (Petrosolium 
sativum) e tirica (Cyperus rotundus). Apenas a rizosfera da alface teve esse favorecimento. No entanto, a diversidade tanto de Bacillus spp. quanto de Pseudomonas spp. é influenciada pela rizosfera em que se desenvolvem (Coelho, 2006). A mesma conclusão chegaram Freitas e Vildoso (2004), em trabalho com três espécies cítricas (Citrus spp.).

Em relação ao Bacillus spp. manteve-se o adensamento em quase todos os tratamentos, após aplicação do efluente no solo, excluindo-se o feijão preto que apresentou uma redução de 50\% no valor médio de quantidade e colônias. Para esse resultado ainda não temos uma interpretação.

Acredita-se que a maior quantidade de rizobactérias Bacillus spp. verificada mesmo após o encerramento do ciclo das plantas, é uma resposta direta a maior resistência desse gênero formação de endósporos - à exposição aos raios solares.

Na Figura 7 são apresentados os resultados dos valores médios de unidades formadoras de colônias por grama de solo, obtidos nas análises microbiológicas de amostras de solo, 60 dias após a primeira irrigação com o efluente e com desenvolvimento de 120 dias de ciclo vegetativo das culturas.

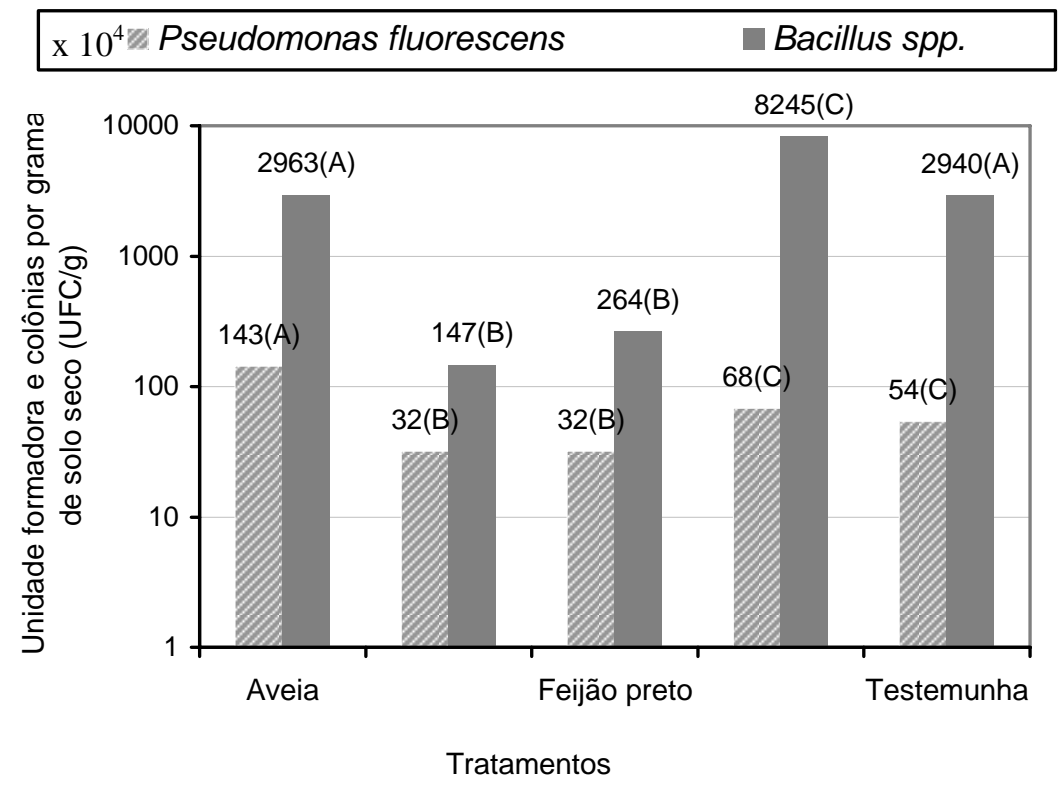

Figura 7. Valores médios de Unidades formadoras de colônias de Pseudomonas fluorescens e Bacillus spp. na camada de 0-20 cm de profundidade de solo cultivado com diferentes culturas e testemunha, 60 dias após a primeira aplicação de efluente de esgoto doméstico tratado. Médias seguidas de letras maiúsculas iguais não diferem significativamente entre si pelo teste de Duncan a 5\% de probabilidade.

Os resultados obtidos 60 dias após a primeira irrigação, ou seja, vinte dias após a terceira aplicação de efluente, indicaram uma notável redução no número de colônias de Pseudomonas fluorescens em quase todos os tratamentos, excluindo-se o tratamento testemunha, o qual não apresentou alterações significativas. Nessa época, todas as culturas já haviam encerrado seu ciclo vegetativo de 120 dias, portanto, estavam prontas para a colheita.

De acordo com estudos de Gamliel e Katan, (1991) a solarização do solo em campo reduziu significativamente populações de Pseudomonas fluorescens, entretanto, após o semeio de tomateiros em solos solarizados, a bactéria rapidamente colonizou a rizosfera e as raízes das plantas. Dessa forma, pode-se deduzir que a seção de produção de exsudados pelas rizosferas aliada à redução do sombreamento causado pelo secamento da plantas possibilitou 
uma maior exposição de área de solo à radiação solar, elevando a temperatura e colaborando para a redução de P.fluorescens.

Em relação à quantidade de Bacillus spp., assim como aconteceu com Pseudomonas fluorescens, verificou-se uma elevada redução de unidades formadoras de colônias nos tratamentos, excluindo-se a aveia, na qual se registrou um acréscimo de $1.8 \times 10^{4}$ para 2,9 $\mathrm{x} 10^{4} \mathrm{UFC}^{-1} \mathrm{~g}^{-1}$. Esse resultado também exige maior investigação para se chegar a uma interpretação conclusiva.

\section{CONCLUSÕES}

Concluiu-se com este experimento que o adensamento das rizobactérias Pseudomonas fluorescens e Bacillus spp. em unidades formadoras de colônias por grama de solo (UFCs.g ${ }^{-1}$ ) está diretamente relacionado à aplicação do efluente de esgoto tratado e, também, ao ciclo vegetativo das plantas.

A eficiência alcançada na redução da concentração de coliformes termotolerantes em número mais provável por $100 \mathrm{~mL}$ de água residuária (NMP.100 $\mathrm{mL}^{-1}$ ), após aplicação do efluente de esgoto no solo, pode estar relacionada à atuação das rizobactérias, por meio de predação, competição por espaço e nutrientes e atuação de sideróforos; pode também estar relacionada às substâncias exsudadas pelas rizosferas de diferentes culturas e, ainda, estar relacionada à influência de fatores físicos externos, principalmente, temperatura ambiente elevada e baixa umidade do solo.

\section{REFERÊNCIAS}

AMERICAN PUBLIC HEALTH ASSOCIATION (APHA). Standard methods for the examination of water and wastewater. 20. ed. Washington: APHA. AWWA. WEF, 2000 .

BECKER, J. O.; ZAVALETA-MEJIA, E.; COLBERT, S. F.; SCHROTH, M. N.; WEINHOLD, A. R.; HANDOCK, J. C.; VAN GUNDY, S. D. Effect of rhizobacteria on root-knot nematodes and gall formation. Annual Review of Phytopatholy, v. 78, p. 1466-1469, 1988.

BENITE, A. M. C.; MACHADO, S. P. Sideróforos: uma resposta dos microrganismos. Química Nova, Rio de Janeiro, v. 25, n. 6B, p. 1155-1164, 2002.

BUTLER, R. G.; ORLOB, G. T.; McGAUHEY, P. H. Underground movement of bacterial and chemical pollutants. Journal of the American Water Works, v. 46, p. 97-111, 1954.

CHERNICHARO, C. A. L. Princípios do tratamento biológico de águas residuárias: tratamentos anaeróbios. Belo Horizonte: Departamento de Engenharia Sanitária/UFMG, 1997. 246p. Vol. 5.

CLAYS-JOSSERAND, A.; LEMANCEAU, P.; PHILIPPOT, L.; LENSI, R. Influence of two plant species (flax and tomato) on the distribution of nitrogen dissimilative abilities within fluorescent Pseudomonas spp. Applied and Environmental Microbiology, v. 61, n. 5, p. 1745-1749, 1995.

COELHO, L. F. Interação de Pseudomonas spp. e de Bacillus spp. com diferentes rizosferas. 2006. 60f. Dissertação (Mestrado em Agricultura Tropical e Subtropical) Instituto Agronômico de Campinas IAC, Campinas, 2006. 
DINARDI, A. L. Fitorremediação: o uso de plantas na melhoria da qualidade ambiental. São Paulo: Oficina de Textos, 2007. p. 14.

FONSECA, M. C. C. Isolamento e caracterização morfológica de pseudomonas spp. Fluorescentes nativas em sistemas de produção agrícola. Seropédica: EMBRAPA Agrobiologia, 2000. Comunicado Técnico n. 43. p. l-4.

FREITAS, S. S.; VILDOSO, C. I. A. Rizobactérias e promoção do crescimento de plantas cítricas. Revista Brasileira de Ciência do Solo, v. 28, p. 987-994, 2004.

FREITAS, S. S.; SILVEIRA, A. P. D. Microbiota do solo e qualidade ambiental. Campinas: Instituto Agronômico de Campinas - IAC, 2007. 317p.

GAMLIEL, A.; KATAN, J. Involvement of fluorescent pseudomonads and other microorganisms in increases growth response of plants in solarizes soils. Annual Review of Phytopathology, v. 81, p. 494-502, 1991.

HABTE, M.; BYAPPANAHALLIU, M. N. Dependency of cassava. (Manihot sculenta Crantz) an vesicular-arbuscular mycorrhizal fungi. Mycorrhiza, v. 4, p. 241-245, 1994.

KÖPEN, W. Climatologia. México: Fondo de Cultura Económica, 1948.

McGAUHEY, P. H.; KRONE, R. B. Soil mantle as a wastewater treatment system. Sanitary Engineering Research Laboratory. Berkeley: University of California, 1967. Report n. 67-11.

SIKORA, R. A. Interrelationship between plant health promoting rhizobacteria, plant parasitic nematodes and soil microorganisms. Med. Fac. Kandbouww. Rijksuniv. Gent, v. 53, n. 2b, p. 867-878, 1992.

STAINER, R. Y.; PALLERONI, N. J.; DOUDOROFF, M. The aerobic Pseudomonads: a toxic study. Journal of General Microbiology, v. 43, p. 159-271, 1966.

SWIFT, M. J.; HEAL, O. W.; ANDERSON, J. M. Decomposition in terrestrial ecosystems. Oxford: Blacwell, 1979. 372p.

STIRLING, G. R. Biological control of plant parasitic nematodes: progress, problems and prospects. Wallingford: Oxon, 1991.

ZAVALETA-MEJIA, E.;VAN GUNDY, S. D. Effects of rhizobacteria on Meloidogyne infection. Journal of Nematology, n. 14, p. 475-476, 1982. 